\title{
Pedicle Screws Fixation of Thoraco-Lumbar Fractures Experience in Qatar
}

\section{Abdulnasser Alyafei ${ }^{1}$, Ghanem Al Sulaiti ${ }^{1}$, Nissar Shaikh ${ }^{2}$, Sirajelddin Belkhair ${ }^{1}$, Ahmed Quateen ${ }^{1}$, Surya Batas $^{1}$, Aisha AL Kubaisi ${ }^{1}$, Ghaya AL Rumahi ${ }^{1}$, Alaalden $^{1}$, Husham Abdul Rahman ${ }^{4}$, Ahmed Own ${ }^{3}$, Ali Raza $^{1}$ and Hassan AL Thani ${ }^{4}$}

${ }^{1}$ Neurosurgery Section, Department of Neurosciences, Hamad Medical Corporation, Doha, Qatar

${ }^{2}$ Surgical Intensive Care Unit, Hamad Medical Corporation, Doha, Qatar

${ }^{3}$ Neuroradiology, Department of Neurosciences, Hamad Medical Corporation, Doha, Qatar

${ }^{4}$ Head Vascular \& Trauma Surgery, Hamad Medical Corporation, Doha, Qatar

*Corresponding author: Nissar Shaikh, Surgical Intensive Care Unit, Hamad Medical Corporation, Doha, Qatar

\begin{abstract}
Thoracolumbar injury is one of the most common spine injuries. The injury manifesting as neurologic deficit usually requires surgery because of the underlying spinal instability and/or neural compression. The objectives of surgical treatment are to restore the biomechanical stability of the spine and/or to achieve neural decompression.
\end{abstract}

Aim: The aim of the study was to evaluate short-term outcomes in patients with symptomatic vertebral injury, underwent posterior instrumentation surgery in the acute stage.

Patients and methods: All patients underwent fixation of thoracolumbar injury from November 2007 to October 2018 were included in the study.

Results: A total of 255 patients with unstable fracture were enrolled. Two hundred nineteen $(85.88 \%)$ were male and $36(14.11 \%)$ females mechanism of injury, $141(55.29 \%)$ patients fall from height. Eighty-two $(32.15 \%)$ patients involved road traffic accident. Thirty-two (12.54\%) patients had direct trauma. Seventy-two (28.23\%) patients had American ASIA-A. Fifteen (5.88\%) patients ASIA-B. Fortyone (16\%) patients ASIA-C. Fifty-one (20\%) patient.

ASIA-D and $76(29.8 \%)$ patients ASIA-E. preoperatively evaluated. All patients had pre-operative CAT SCAN \& 90\% pre-operative Magnetic resonance imaging. T12 and L1 $60.6 \%$, involved, L1 37.6\%, T12 23\%. L2 12.8\%.

All patients underwent posterior instrumentation surgery using pedicle screws and connecting rods, either short or long segment. No patient experienced neurologic deterioration perioperatively. Postoperative recovery evaluated heavily depended on the preoperative neurologic status: Fifty-seven
(22/35\%) patients improved neurologically according to ASIA SCALE. Six patients from ASIA A to $C, 2$ patients from ASIA A to B, 2 patients from ASIA A to D, 8 patients from $B$ to $C, 5$ patients from $B$ to $D$. Nineteen patients from $C$ to $D, 14$ patients from $D$ to $E$. In general, early surgery better than late surgery for neurological recovery. Complications rate $4.7 \%$ but not major complications, none suffered death or permanent morbidity, $3.9 \%$ superficial-wound infection, one patient $0.4 \%$ mal-position of screws, \& one patient $0.4 \%$ pulmonary embolism. X-ray follow up satisfactory except 16 patients $6 \%$ mild kyphosis. 2 patients $0.8 \%$ moderate kyphosis.

Conclusion: The Posterior instrumentation surgery is a safe and efficacious treatment for thoraco- lumber fractures.

\section{Keywords}

ASIA, Acute stage, Decompression, Posterior instrumentation surgery, Thoracolumbar spinal injury

\section{Introduction}

Thoracolumbar injury is one of the common spine injuries. Accidental fall and motor vehicle accident are the two most common causes of this injury $[1,2]$. Treatment of thoracolumbar injury depends on several clinical factors including age of the patient, mechanism of injury, degree of spinal canal compromised by bony fragments, degree of integrity of the posterior spinal elements, and presence of neurologic deficit [3-5]. Patients with thoracolumbar injury manifesting as neurologic deficit generally require surgical treatment,

Citation: Alyafei A, Al Sulaiti G, Shaikh N, Belkhair S, Quateen A, et al. (2021) Pedicle Screws Fixation of Thoraco-Lumbar Fractures Experience in Qatar. Neurosurg Cases Rev 4:076. doi.org/10.23937/26434474/1710076

Accepted: September 01, 2021; Published: September 03, 2021

Copyright: (C) 2021 Alyafei A, et al. This is an open-access article distributed under the terms of the Creative Commons Attribution License, which permits unrestricted use, distribution, and reproduction in any medium, provided the original author and source are credited. 
because they almost invariably have underlying spinal instability and/or neural compression $[4,6]$. Therefore, the Objectives of surgical treatment are to restore the biomechanical stability of the spine and/or to achieve neural decompression. Several surgical approaches are available for this type of injury, including the anterior, Antero-lateral approach, posterior approach, and combination of both [5-7].

Posterior distraction implants have gained popularity for a long time in the management of posterior ligamentous disruptions and/or anterior bony injuries. The problem of long fixation segment remains. This problem was still present, to a lesser extent, with plate fixation. The principle of screw anchorage to the pedicles, although not without complications, has popularized the concept of short segment fixation. The new modalities of implants can now serve the same goals i.e. to maintain the stabilization and unload the affected segment until healing occurs $[1,2,8]$.

Aim of this study was to evaluate the results of management of unstable injuries of the thoracolumbar spine, with or without neurological deficits, by posterior stabilization using the principles of short and long segments pedicle screws fixation.

\section{Materials and Methods}

\section{Patients}

Two Hundred Fifty-Five patients with thoracolumbar fractures underwent surgical treatment at Hamad General Hospital, after sustaining high energy trauma between November 2007 - November 2018.

All patients Present with or without neurologic deficit. All of them unstable fractures came to the emergency room. All patients were treated by posterior approach pedicle screw fixation. Most of them underwent surgery within 48 hours of admission, $30 \%$ admission to the ward isolated spinal fractures and $70 \%$ admission to ICU. Need or asses others injury. The clinical characteristics and outcomes of the 255 patients were investigated retrospectively by meticulous review of medical charts, operative records, and radiographic images.

\section{Surgical treatment}

The patients were positioned prone on a Jackson table under general anesthesia. Short or long segments, either minimal techniques (MIS) used fluoroscopy or navigation systems or open techniques traditional or using navigation systems were exposed periosteal with a standard midline approach.

The superior and inferior boundaries and the transverse processes on either side of the vertebrae were then identified. The screws were placed through the pedicles under $C$ arm $\mathrm{x}$-ray guidance or navigation system guidance.

The entry point to pedicle was the intersection of a line bisecting the transverse process with the lateral margins of the facet joint complex. Tapping of the resultant tract was done. Screws of appropriate length ad diameter were then inserted. If decompression was considered necessary, the lamina over the fractured vertebra was removed.

The screws were connected to the titanium rods bilaterally. Maximal effort was made to achieve optimal alignment. The rods were then connected with a crosslink or without. Postoperatively, all patients underwent a rigorous rehabilitation program, and. Postoperative $x$-ray done for all of patients and deformity was measured above and below.

\section{Data collection and analysis}

All patients with thoracolumbar fractures underwent surgical treatment at Hamad General Hospital, after sustaining high energy trauma between November 2007 - November 2018.

Data were entered and analyzed using SPSS version 23. Categorical variables were reported using numbers (n) and percentages (\%). Continuous variables are reported as mean $\pm \mathrm{SD}$, and categorical variables were represented as frequency and percentage. The Kolmogorov-Smirnov test proved these variables to be normally distributed. Between-group comparisons were performed by using the chi-square test for categorical variables and the t-test for continuous variables. Differences were considered statistically significant at $p$ $\leq 0.05$.

\section{Results}

\section{Clinical presentation}

Majority of patients had vertebral injury due to fall (141/55\%) (Table 1). The demographic data for the 255 patients are summarized in Table 2. 219 males' $85.88 \%$ and 36 females $14.11 \%$, were aged between 19 to 68 years, $45 \% \leq 30$ yrs. Causes of thoracolumbar fractures were: fall from height 141 patients $(55.29 \%)$, motor vehicle accident 82 patients (32.15\%), and direct 32

Table 1: Mode analysis of injury.

\begin{tabular}{|l|l|l|}
\hline \multicolumn{3}{|c|}{ Analysis of the injury } \\
\hline Findings & No. & $\%$ \\
\hline Mode of Injury & & \\
Fall from height & 141 & $55.29 \%$ \\
Motor vehicle & 82 & $32.15 \%$ \\
Direct & 32 & $12.54 \%$ \\
\hline
\end{tabular}

Table 2: Patients demographic data.

\begin{tabular}{|l|l|}
\hline Male: Female & $6: 1$ \\
\hline Males & $219 / 85.88 \%$ \\
\hline Females & $36 / 14.11 \%$ \\
\hline Hospital stays & $3-70$ Days \\
\hline
\end{tabular}




\section{Anatomical level}

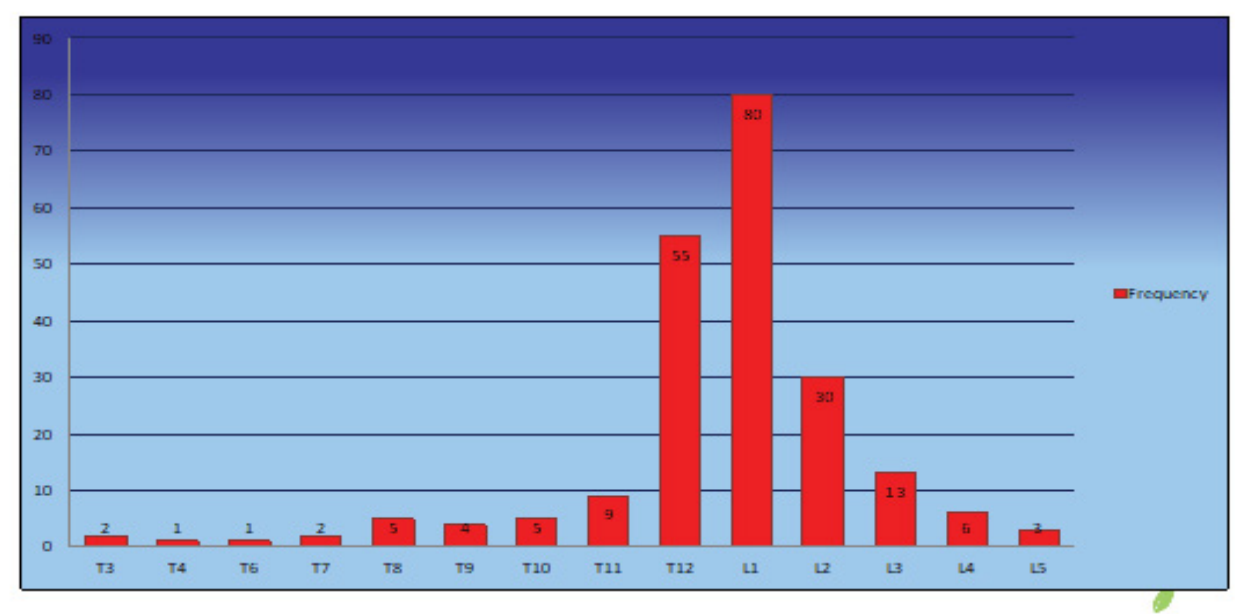

Affected Vertebra
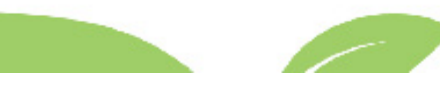

Figure 1: Anatomical level of vertebral injury.

\begin{tabular}{|c|c|c|c|c|c|}
\hline $\mathbf{A}$ & 62 & 2 & 6 & 2 & \\
\hline B & & 2 & 8 & 5 & \\
\hline C & & & 22 & 18 & 1 \\
\hline D & & & & 37 & 14 \\
\hline $\mathbf{E}$ & & & & & 57 \\
\hline & $\mathbf{A}$ & B & $\mathbf{C}$ & D & $\mathbf{E}$ \\
\hline
\end{tabular}

Figure 2: Diagram showing the pre- and postoperative neurologic status of 195 patients, using the American Spinal Injury Association (ASIA) classification. The postoperative status of each patient was evaluated.

Table 3: Neurological status on admission.

\begin{tabular}{|l|l|l|}
\hline & No. & $\%$ \\
\hline A $=$ Complete & 72 & 28.23 \\
\hline B $=$ Complete motor, Sensory sparing & 15 & 5.88 \\
\hline C $=$ Partial motor, Useless & 41 & 16 \\
\hline D $=$ Partial motor, Useful & 51 & 20 \\
\hline E $=$ Normal & 76 & 29.8 \\
\hline
\end{tabular}

patients $12.54 \%$. Hospital stay ranged from 3 to 70 days.

\section{Type and anatomical}

The distribution of the type and anatomical level of $T L$ injury is illustrated in Figure 1, and it is mainly L1 and T12.

\section{Preoperative neurologic status}

The neurological deficit (Table 3) in each patient was evaluated by the American Spinal Injury Association (ASIA) classification (Table 4). Preoperatively, 72 patients had ASIA Grade A deficits, 15 had Grade-B, 41 had Grade-C, 51 had Grade-D, and 76 had grad E.
Table 4: American spinal injury association classification.

\begin{tabular}{|l|l|}
\hline Grade & Neurological deficit \\
\hline A & $\begin{array}{l}\text { No sensory or motor function preserved in the } \\
\text { sacral segments S4-S5 }\end{array}$ \\
\hline B & $\begin{array}{l}\text { Sensory, but not motor, function is preserved } \\
\text { below the neurologic level and extends through } \\
\text { sacral segments S4-S5. }\end{array}$ \\
\hline C & $\begin{array}{l}\text { Motor function is preserved below the neurologic } \\
\text { level, and most key muscles below the neurologic } \\
\text { level have a muscle grade less than 3. }\end{array}$ \\
\hline D & $\begin{array}{l}\text { Motor function is preserved below the neurologic } \\
\text { level, and most key muscles below the neurologic } \\
\text { level have muscle greater than or equal to 3. }\end{array}$ \\
\hline E & \begin{tabular}{l} 
Sensory and motor functions are normal. \\
\hline
\end{tabular} \\
\hline
\end{tabular}

\section{Surgical treatment}

Surgery was performed for most of them within 48 HOURS of admission in most of them, in whom surgery was delayed after admission because of the associated injuries. 


\section{Postoperative neurologic status}

No patient experienced neurologic deterioration in the immediate postoperative period. The follow-up period after discharge was done $70 \%$ of them.

The patients underwent routine neurologic examination after discharge. The overall results improved 57 cases $22.35 \%$, are summarized in Figure 2. 72 patients with Grade-A deficits. 10 patients improved, 6 patients of them became grade C, 2 patient was became Grade-B, and 2 patients became Grade $D$.

15 patients with Grade B. 13 patients improved 8 improve to $C$ and 5 to Grade-D.

41 patients GRADE C, 19 patients improved 18 to $D$ and 1 to $E$.

51 patients GRADE D, 14 patients improved to $E$.

All patients with grade-E maintained their grade and showed no deterioration.

\section{Complications}

A total of 12 cases of complications $4.7 \%$ that occurred in our series are summarized in Table 5 and Table 6. Intraoperative complicated occurred in one patient who had misplacement of a pedicle screw, which violated the medial pedicle wall and partially protruded into the spinal canal. The misplaced pedicle screw in case of Grade A did and repositioning of the screw was replaced after four days, it was T3. Postoperative complications of infection occurred in 10 patients $3.9 \%$. Superficial wound infection and 1 patient $0.4 \%$ developed pulmonary embolism after operative treatment and he was cured.

\section{Discussion}

Recently, treatment of thoracolumbar fracture has undergone a significant paradigm shift. Particularly, the role of surgical treatment for burst fractures has become

Table 5: Complications.

\begin{tabular}{|l|l|}
\hline Intraoperative & Postoperative \\
\hline Malposition pediclescrew: 1 & $\begin{array}{l}\text { Superficial wound infection: } 4 \\
\text { Pulmonary embolism:1 }\end{array}$ \\
\hline
\end{tabular}

Table 6: Patients outcome.

\begin{tabular}{|l|l|l|l|l|}
\hline AA & AB & AC & AD & AE \\
\hline 62 & 12 & 6 & 2 & -- \\
\hline BA & BB & BC & BD & BE \\
\hline-- & 2 & 8 & 5 & -- \\
\hline CA & CB & CC & CD & CE \\
\hline-- & -- & 22 & 18 & $-1-$ \\
\hline DA & DB & DC & DD & DE \\
\hline-- & -- & -- & 37 & 14 \\
\hline EA & EB & EC & ED & EE \\
\hline-- & -- & -- & -- & 57 \\
\hline
\end{tabular}

more obscure $[9,10]$. Conservative management may be sufficient for patients with stable burst fracture who present without neurologic deficit as shown in a prospective, randomized study in which surgical treatment had no major long-term advantage compared with non-operative treatment $[9,11,12]$. In contrast, surgery is generally warranted for patients presenting with neurologic deficit, because they almost invariably have underlying biomechanical instability and/or neural compression $[11,13]$. Therefore, the main objectives of surgical treatment for patients with symptoms are restored of the biomechanical stability/physiological alignment and/or neural decompression. The degree of neurologic recovery after surgery largely depended on the preoperative neurologic status in the present study; patients with ASIA Grade-A deficits usually had a limited neurologic recovery, whereas some with Grade-C or $D$ became ambulatory. The trend has previously been reported by many authors $[8,9,14,15]$.

There have been lengthy debates on whether the anterior or posterior approach should be used for unstable thoracolumbar fractures [16]. The choice of surgical approaches has mostly been anecdotal, influenced heavily by the surgeon's preference and education. In our institution, symptomatic fractures are approached from the posterior direction. The short-term outcomes were generally satisfactory with low rates of serious complications, which have made us convinced that the stand-alone posterior approach may be sufficient for most patients who present with a non-progressive neurologic deficit unless some transitional zone [17-20]. Although there has been concern whether the stand-alone posterior surgery can be adequately stabilized the two or three columns the thoracolumbar fracture [21]. The advocates of anterior surgery have also reported satisfactory results for symptomatic patients operated on from the anterior approach only [22,23]. Although randomized, controlled studies would clarify which approach is more suited for everyone, such studies to compare the efficacy of the two approaches for patients with symptomatic thoracolumbar fracture have never been conducted $[22,23]$. In that context, a spine surgeon may be allowed to adopt the approach with which he or she feels more comfortable in many circumstances. Generally, the posterior approach is tough to be less effective in neural decompression compared with the anterior approach $[6,24,25]$. In experienced hands, adequate spinal canal decompression can be achieved with a combination of laminectomy and ligamentotaxis. On the other hand, the posterior approach was essential because of the presence of posterior ligamentous disruption.

The number of thoracolumbar vertebral segments to be incorporated into the posterior instrumental fixation also remains controversial. In our institution, we are doing both short and long segments, we did not find significates different unless in some cases of transitional 
zone. Although the range of motion may be diminished after a long segment posterior fixation, the risk of hardware failure is smaller compared with a shortsegment posterior fixation that is, fixation incorporating the two vertebrae (one above and one below the fractured segment). Laboratory as well as clinical studies revealed that short-segment posterior fixation may be biomechanically incompetent to support the destroyed or weakened vertebral column in patients with unstable burst fracture $[26,27]$. However, shortsegment posterior fixation is superior to long-segment fixation in that the range of motion is less compromised and the risk of pedicle screw related complications is smaller because of a short segment fixation uses half the number of pedicle screws $[20,28]$. The injection of polymethyl methacrylate into the fracture vertebral body to strengthen the anterior column in combination with a short segment posterior fixation has been improvised to overcome the shortcomings of conventional shortsegment fixation $[7,29]$. The technique may be beneficial in selected patients.

There are several limitations in the present study. Firstly, this is a retrospective case series, without different treatment methods for comparison. Although we are convinced that posterior instrumentation surgical is a safe and efficacious treatment, it cannot be determined whether the posterior approach is superior to the anterior approach, or vice versa. Secondly, because of the limited duration of the follow-up period, the long-term outcomes, including the quality of life parameters, of the patients could not be evaluated.

\section{Conclusion}

The Posterior instrumentation surgery is a safe and efficacious treatment for thoraco-lumber fractures with lesser complications.

\section{References}

1. Alanay A, Acaroglu E, Yazici M, Oznur A, Surat A (2001) Short-segment pedicle instrumentation of thoracolumbar burst fractures: Does transpedicular intracorporeal grafting prevent early failure? Spine 26: 213-217.

2. Been HD, Bouma GJ (1999) Comparison of two types of surgery for thoracolumbar burst fractures: Combined anterior and posterior stabilization vs. posterior instrumentation only. Acta Neurochir (Wjen) 141: 349-357.

3. Eichholz KM, Hitchon PW, From A, Rubenbauer $P$, Nakamura S, et al. (2004) Biomechanical testing of anterior and posterior thoracolumbar instrumentation in the cadaveric spine. Invited submission from the Join Section Meeting on Disorders of the Spine and Peripheral Nerves, March 2004. J Neurosurg Spine 1: 116-121.

4. Gertzbein SD (1992) Scoliosis research society. Multicenter spine fracture study. Spine 17: 528-540.

5. Gurwitz GS, Dawson JM, McNamara MJ, Federspiel CF, Spengler DM (2004) Biomechnical analysis of three surgical approaches for lumbar burst fractures using short-segment instrumentation. Spine 18: 977-982.
6. Hitchon PW, Torner JC, Haddad SF, Follett KA (1998) Management options in thoracolumbar burst fractures. Surg Neurol 49: 619-626.

7. Hurlbert RJ, Moulton R (2002) Why do you prescribe methylprednisolone for acute spinal cord injury? A Canadian perspective and a position statement. Can J Neurol Sc 29: 236-239.

8. Katonis PG, Kontakis GM, Loupasis GA, Algizakis AC, Christoforakis JI, et al. (1999) Treatment of unstable thoracolumbar and lumbar spine injuries using CotrelDubousset instrumentation. Spine 24: 2352-2357.

9. Kawanishi $M$, Itoh $Y$, Satoh $D$, Matsuda $N$, Kamo $M$, et al. (2006) The surgical treatment of injuries to the thoracolumbar spine. Sekizui Geka 20: 25-31.

10. Kramer DL, Rodgers WB, Mansfield F (1995) Transpedicular instrumentation and short segment fusion of thoracolumbar fractures: A prospective study using a single instrumentation system. J Orthop Trauma 9: 499-506.

11. Magerl F, Aebi M, Gertzbein SD, Harms J, Nazarian S (1994) A comprehensive classification of thoracic and lumbar injuries. Eur Spine J 3: 184-201.

12. McLain RF (2006) The biomechanics of long versus short fixation for thoracolumbar spine fractures. Spine S70-S79.

13. McLain RF, Sparling E, Benson DR (1993) Early failure of short-segment pedicle instrumentation for thoracolumbar fractures. A preliminary report. J Bone Joint Surg 75: 162167.

14. Mikles MR, Stchur RP, Graziano GP (2004) Posterior instrumentation for thoracolumbar fractures. J Am Acad Orthop Surg 12: 424-435.

15. Priebe MM, Waring WP (1991) The interobserver reliability of the revised American Spinal Injury Association standards for neurological classification of spinal injury patients. A J Phys Med Rehabil 70: 268-270.

16. Sasso RC, Best NM, Reilly TM, McGuire RA Jr (2005) Anterior-only stabilization of three-column thoracolumbar injuries. J Spinal Disord Tech 18: S7-S14.

17. Shen WJ, Lu TJ, Shen YS (2001) Nonoperative treatment versus posterior fixation for thoracolumbar junction burst fractures without neurological deficit. Spine 26: 1038-1045.

18. Tezeren G, Kuru I (2005) Posterior fixation of thoracolumbar burst fracture: Short segment pedicle fixation versus long segment instrumentation. J Spinal Disord Tech 18: 185188.

19. Verlaan JJ, van de Kraats EB, Oner FC, vanWalsum T, Niessen WJ, et al. (2005) Bone displacement and the role of longitudinal ligaments during balloon vertebroplasty in traumatic thoracolumbar fractures. Spine 30: 1832-1839.

20. Wood K, Buttermann G, MehbodA, Garvey T, Jhanjee R, et al. (2003) Operative compared with nonopeartive treatment of a thoracolumbar burst fracture without neurological deficit. A prospective, randomized study. J Bone Joint Surg Am 85: 773-781.

21. Wood KB, Bohn D, Mehbood A (2005) Anterior versus posterior treatment of stable thoracolumbar burst fractures without neurologic deficit: A prospective, randomized study. J Spinal Disord Tech 18: S15-S23.

22. Yu SW, Fang KF, Tseng IC, Chiu YL, Chen YJ, et al. (2002) Surgical outcomes of short-segment fixation for thoracolumbar fracture dislocation. Chang Gung Med J 25: 253-259. 
23. Stewart G, Sachs BL (1996) Patient outcomes after reoperation on the lumbar spine. J Bone Joint Surg (Am) 78: 706-720.

24. Karlstrom G, Olerud S, Sjostrom L (1990) Transpedicular fixation of thoracolumbar vertebral fractures. Clin Orthop Relat Res 20: 285-300.

25. Adreychick DA, Alanderm DH, Senica KM, Stauffer ES (1996) Burst fractures of the second through fifth lumbar vertebrae; clinical and radiographic results. J Bone Joint Surg (Am) 7: 1156-1166.

26. Chan DP, Seng NK, Kaan KT (1993) Nonoperative treatment in burst fractures of the lumbar spine (L2-L5) without neurologic deficits. Spine 18: 320-325.
27. Bradford DS, McBride GG (1987) Surgical Management of thoracolumbar spine fractures with incomplete neurologic deficits. Clin Orthop Relat Res 218: 201-216.

28. Crites BM, Moorman CT, Hadackerm WT Jr. (1998) Spine injuries associated with falls from hunting trees stands. $J$ South Orthop Assoc 7: 241-245.

29. Yazici M, Gulman G, Sen S, Tilki K (1995) Sagittal contour restoration and canal clearance in burst fractures of the thoracolumbar junction (T12-L1): The efficacy of timing before surgery. K Orthop Trauma 9: 491-498. 